\title{
Clinical Significance and Analytical Determination of Trace Amounts of Selenium in Human Blood- Spectrophotometeric Technique
}

\author{
Ranjana S. Khanna ${ }^{1}$, Reena Negi ${ }^{2}$, Deepti Pande ${ }^{2}$ and Hari D. Khanna ${ }^{2 *}$ \\ ${ }^{1}$ Department of Chemistry, Faculty of Science; ${ }^{2}$ Department of Biophysics, Institute of Medical Sciences Banaras Hindu \\ University, Varanasi - 221 005, India
}

\begin{abstract}
Selenium is an essential trace element that is important in proper immune system functioning and in free radical control. Selenium protects against heart weakness and degeneration. It is crucial for optimal health and detoxification. Selenium is required for the production of thyroid hormones. The body only needs a small amount. Nevertheless, the selenium mineral is an essential mineral which the body requires on a daily basis. The objective of the work concerns the proposal and development of the technique for the measurement of selenium levels in the human blood samples by a simple spectrophotometeric determination in diseased and health conditions.
\end{abstract}

Keywords: Selenium determination, Clinical significance, Spectrophotometeric method.

\section{INTRODUCTION}

Selenium is an essential trace element in humans and animals. Its only established function in humans is the antioxidant activity of glutathione peroxidase, a selenoenzyme. Severe prolonged deficiency may cause a fatal cardiomyopathy. Iatrogenic causes of selenium deficiency include parenteral and enteral nutrition. Low plasma selenium is also found in malabsorption, cystic fibrosis, rheumatoid arthritis, neoplasia, and other varied clinical disorders. Death has resulted from a single massive ingestion of selenium, while chronic excessive intake causes skin, nail, and hair pathology. Precise knowledge of amounts of selenium is required for accurate assessment of the environmental and biological impact of selenium.

The most commonly used methods for the selenium quantitation are atomic absorption spectrometry, molecular fluorescence spectrometry and spectrophtometry. The spectrophotometric determination of traces of selenium is generally based on two types of reaction. First type involves the reduction of selenium (IV) to elemental selenium, often with the simultaneous production of a colored oxidation product. In the second method, a colored or fluorescent piazoselenol is formed when selenium (IV) reacts with an aromatic odiamine.

We propose a simple, selective and sensitive spectrophotometric method for the determination of trace amounts of selenium (IV) based on the oxidation of phenylhydrazine -psulphonic acid and coupling reactions in the human blood plasma /serum samples. This method has been applied for the determination of trace amounts of selenium in plant material, polluted water and soil samples [1] and has been employed in the current work for human blood sera.

*Address correspondence to this author at the Department of Biophysics, Institute of Medical Sciences, Banaras Hindu University, Varanasi - 221 005, India; Tel: +91-9450710446; Fax: +91-542-2367568;

E-mail: hdkhanna@yahoo.co.in

\section{METHODS AND MATERIALS}

\section{A. Collection of Samples}

About $15 \mathrm{ml}$ of cord blood was collected in sterilized glass tubes just after the second stage of labor. Plasma was stored at $-20^{\circ} \mathrm{C}$ until analyzed. The study population comprised of sixty two low birth weight new born babies with a weight less than $2500 \mathrm{~g}$ selected from the outpatient Department of Pediatrics, University Hospital, Banaras Hindu University, Varanasi. Forty new born babies near or full term weighing more than $2500 \mathrm{~g}$ served as controls.

40 cases of chronic myeloid leukemia who were admitted either in Medicine ward, Department of Medicine, University Hospital, Banaras Hindu University, Varanasi. or reported for routine follow up in hematology and oncology clinics respectively were included in the study. Informed consent was taken from the individuals, parents or attendants in all cases.

\section{B. Experimental Procedure \\ Reagents}

All chemicals used were of analytical grade. Stock solution of selenium (IV) was prepared by dissolving $0.143 \mathrm{mg}$ of selenium dioxide in $100 \mathrm{ml}$ of distilled water. Working solutions were prepared by diluting the stock solution with distilled water. Phenylhydrazine -p- sulphonic acid, $0.5 \%$; acetylacetone, $0.5 \% ; \mathrm{HCl}, 4 \mathrm{M}$ and $\mathrm{NaOH}, 6 \mathrm{M}$ were used.

\section{Apparatus}

A UV-visible spectrophotometer was used for the absorbance measurements and a cyber scan $510 \mathrm{pH}$ meter was used.

\section{Assay of Selenium}

An aliquot of a solution containing known amount of selenium was transferred into $40 \mu \mathrm{L}$ of $4 \mathrm{M} \mathrm{HCl}$ and $30 \mu \mathrm{L}$ of $0.5 \%$ phenylhydrazine $-\mathrm{p}$ - sulphonic acid and the mixture 
Table I. Mother and Neonatal Characteristics

\begin{tabular}{|c|c|c|}
\hline Characteristics & LBW(<2500g) & Control (>2500g) \\
\hline \hline Number & 62 & $27 \pm 5$ \\
\hline Age(yrs) & $26 \pm 3$ & $37.8 \pm 1.7$ \\
\hline Gestational age(weeks) & $35.9 \pm 2.9$ & $2944 \pm 347$ \\
\hline Birth weight(g) & $2101 \pm 360$ & $12.548 \pm 1.267$ \\
\hline BMI(Kg/m $\left.{ }^{2}\right)$ & $10.267 \pm 1.634$ & $24 / 16$ \\
\hline m/f Ratio & $34 / 28$ & \\
\hline
\end{tabular}

Value of Mean \pm S.D

BMI $($ Body Mass Index $)=$ weight $/$ height $^{2}$

$\mathrm{M} / \mathrm{F}=$ Male/ Female

Table II. Levels of Selenium $(\mu \mathrm{g} / \mathrm{l})$ in Relation to Birth Weight

\begin{tabular}{|c|c|c|}
\hline & Birth Weight $(\mathbf{g})$ & Levels of Selenium $(\boldsymbol{\mu g} / \mathbf{l})$ \\
\hline \hline 1 & $\operatorname{LBW}(<2000 \mathrm{~g})(\mathrm{n}=18)$ & $19.283 \pm 6.685$ \\
\hline 2 & $\operatorname{LBW}(<2500 \mathrm{~g})(\mathrm{n}=44)$ & $22.070 \pm 5.462$ \\
\hline 3 & $>2500 \mathrm{~g}(\mathrm{n}=40)$ & $35.253 \pm 8.530$ \\
\hline
\end{tabular}

ANOVA F value-48.663

$\mathrm{p}<0.001$ significant

One way analysis (ANOVA) followed BY Tukey's test were used to compare results. The index risk was calculated using the SPSS statistical software package (SPSS 16).

was allowed to stand for $30 \mathrm{~min}$. at room temperature. There after $20 \mu \mathrm{L}$ of $0.5 \%$ acetylacetone and $100 \mu \mathrm{L}$ of $6 \mathrm{M} \mathrm{NaOH}$ solution were added. The total volume was made to $250 \mu \mathrm{L}$ and allowed to stand for $10 \mathrm{~min}$ at room temperature. The absorbance of the azo dye was measured at $490 \mathrm{~nm}$ against the reagent blank [1].

\section{Statistical Analysis}

The data was analyzed using SPSS 16 software. The statistical analysis was done by student' s " $t$ " test and ANOVA followed by Tukey's test to compare results.

\section{RESULTS}

This study was conducted to estimate the levels of selenium in the umbilical cord blood of the low birth weight babies, in the patients of chronic myeloid leukemia and normal healthy controls. The characteristics of mother as well as neonates in respect of maternal age, gestation period, birth weight with the respective BMI of the new borns and male/female ratio is indicated in the Table $\mathbf{I}$. The mean and standard deviation of selenium levels in the plasma in one group of low birth weight new borns with weight $<2000 \mathrm{~g}$ was $19.283 \pm 6.685 \mu \mathrm{g} / \mathrm{l}$ and in another group of low birth weight new borns with weight $<2500 \mathrm{~g}$ was $22.070 \pm$ $5.462 \mu \mathrm{g} / \mathrm{l}$. The mean and standard deviation of selenium levels in the plasma in control group of new borns with weight $>2500 \mathrm{~g}$ was $35.253 \pm 8.530 \mu \mathrm{g} / \mathrm{l}$. The mean and standard deviation of selenium levels in the plasma in low birth weight new borns were significantly lower $(p<0.001)$ than control group of new borns (Table II).
There were 40 cases of chronic myeloid leukemia (CML) and 20 age and sex matched healthy controls. Out of 40 cases, $23(57.5 \%)$ were male and $17(42.5 \%)$ were female. $11(55 \%)$ were male and $9(45 \%)$ were female in control group. Most of patients of CML were in 31-40 yr age group with a mean of $36.7 \pm 11.9$ years. The mean age in control group was $38.3 \pm 11$.6years. The mean duration of symptoms was $3.4 \pm 1.9$ months. The main symptoms were fever and those related to splenomegaly. Mean spleen size assessed by ultrasonography was $21.6 \pm 3.9 \mathrm{~cm}$. Leukocyte counts were elevated in all cases with mean count was $110355 / \mathrm{cu} \mathrm{mm}$. Bone marrow involvement suggestive of CML was found in all cases while Philadelphia chromosomes was present in $16(88 \%)$ patients Table III.

The mean and standard deviation of selenium levels in the serum of in the chronic myeloid leukemia patients were $25.5278 \pm 5.030 \mu \mathrm{g} / \mathrm{l}$. Selenium levels in the serum of chronic myeloid leukemia patients were significantly lower $(\mathrm{p}<0.01)$ than control group (Table IV).

\section{DISCUSSION}

Selenium (Se) plays a key role in the maintenance of normal health in human populations [2]. The cellular biochemistry of Selenium involves the expression of a variety of selenoproteins. Selenium is part of the active site of glutathione peroxidase (GSH-Px), an antioxidant enzyme [3]. It has been demonstrated that, when taken as a supplement, Selenium modulates the cellular response to oxidative stress, inducing a faster restoration of the endogenous antioxidative defense system against the production of reactive oxygen species [4]. Glutathione peroxidase controls the interacellular 
Table III. Characteristics of Chronic Myeloid Leukemia Patients

\begin{tabular}{|c|c|}
\hline Characteristics & Chronic Myeloid Leukemia Cases (n= 40) \\
\hline \hline Male & $23(57.5 \%)$ \\
\hline Female & $17(42.5 \%)$ \\
\hline Mean age (yr) & $36.7 \pm 11.9$ \\
\hline Mean duration of symptoms (months) & $3.4 \pm 1.9$ \\
\hline Mean spleen size (cm) & $21.1 \pm 3.5$ \\
\hline Mean Hb (gm/dl) & $11.1 \pm 1.6$ \\
\hline Mean Leukocyte count (per mm $\left.{ }^{3}\right)$ & 60595 \\
\hline Mean Creatinine (mg/dl) & 0.85 \\
\hline Ph chromosomes $(+)$ & $36(90 \%)$ \\
\hline
\end{tabular}

Table IV. Serum Selenium Values ( $\mu \mathrm{g} / \mathrm{l})$ in Chronic Myeloid Leukemia (CML)

\begin{tabular}{|c|c|c|}
\hline Major Groups & $\begin{array}{c}\text { Mean } \pm \text { S.D } \\
(\boldsymbol{\mu g} / \mathbf{l})\end{array}$ & $\mathbf{p}-$ Value \\
\hline \hline Control & $38.9030 \pm 29.593$ & \multirow{2}{*}{$0.006 *$} \\
\hline Chronic myeloid leukemia (CML) cases & $25.5278 \pm 5.030$ & \\
\hline
\end{tabular}

$* \mathrm{p}<0.01$ statistically significant

level of hydrogen peroxide, reducing the formation of reactive oxygen species that can induce lipid peroxidations with consequent damage to the cellular membranes [5]. Epidemiological studies suggest a low intake of Selenium might predispose an individual to an increased incidence of cardiovascular disorders [6]. There is increasing evidence that selenium deficiency may have several serious short- and longterm medical implications, including impaired immune response, or even cancer [7].

A simple and selective spectrophotometric method for the determination of trace amounts of Selenium (IV) is employed based on the oxidation of phenylhydrazine - $\mathrm{p}$ sulphonic acid and coupling reactions. Selenium (IV) oxidizes phenylhydrazine - p-sulphonic acid into its diazonium salt in acid medium. The diazonium salt is then coupled with acetyl acetone in an alkaline medium, which gives azo dyes with absorption maximum at $490 \mathrm{~nm}$. The method employed for human blood sera or plasma is simple, selective and does not involve any stringent reaction conditions and offers the advantage of color stability for more than $3 \mathrm{hrs}$.

The data derived from this study indicate the trace amounts of selenium present in the umbilical cord blood of low birth weights babies and in healthy babies. The amount of selenium in the new born depends on the selenium status of the mother because low levels of this element in the mother produce low levels in the cord blood [8]. Selenium levels were found to be significantly lower in low birth weight babies in comparison to healthy babies suggesting a need for interest in monitoring the oxidative state of mothers during pregnancy period, especially taking into account that the oxidative level could be involved in later risks of metabolic diseases for both mother and new born [9].
All patients of chronic myeloid leukemia showed low serum selenium levels when compared to controls. Trace element content has been reported to be related to disease states and the trace amounts of selenium element has been suggested to play an important role in cancer, leukemia and other diseases [10].

\section{CONCLUSION}

The purpose of this study was to determine serum selenium levels in health and diseased state with a simple and convenient method that can be employed in a laboratory with minimum facility of spectrophotometer. This information will add to the general knowledge of the metabolism of selenium in humans and thereby help in eventual evolution of the role selenium and other trace element alone or in concert play in disease.

\section{REFERENCES}

[1] Cherian T, Narayana B. A new system for spectrophotometric determination of trace amounts of selenium. Indian J Chem Technol 2006; 13: 222-5.

[2] Savarino L, Granchi D, Ciapetti G, et al. Serum concentrations of zinc and selenium in elderly people: results in healthy nonagenarians/centenarians. Exp Gerontol 2001; 36: 327-39.

[3] Rotruck JT, Pope AL, Ganther HE, Swanson AB, Hafeman DG, Hoekstra WG. Selenium: Biochemical role as a component of glutathione peroxidase. Science 1973; 179: 588-90.

[4] Jozanov-Stankov O, Demajo M, Djujic I, Mandic M. Selenium intake as a modulator of responsiveness to oxidative stress. J Environ Pathol Toxicol Oncol 1998; 17: 251-7.

[5] Burk RF, Levander OA: Selenium. In Modern nutrition in health and disease. $9^{\text {th }}$ ed. Shils ME, Olson J, Shike M, Eds. Baltimore; Lippincott Williams \& Wilkins, 1999; pp. 265-276.

[6] Salonen JT, Alfthan G, Huttunen JK, Pikkarainen J, Puska P. Association between cardiovascular death and myocardial infarction and 
serum selenium in a matched-pair longitudinal study. Lancet 1982; 2:175-9.

[7] Kohrle J, Brigelius-Flohe R, Bock A, Gartner R, Meyer O, Flohe L. Selenium in biology: facts and medical perspectives. Biol Chem 2000; 381:849-64.

[8] Alonso MJL, Barrera AB, de Juan JAC, Bermudez AB, Barrera PB. Selenium levels in related biological samples: Human placenta, maternal and umbilical cord blood, hair and nails. J Trace Elements Med Biol 2005; 19:49-54.
[9] Arguelles S, Machado MJ, Ayala A, Machado A, Hervias B. Correlation between circulating biomarkers of oxidative stress of maternal and umbilical cord blood at birth. Free Radic Res 2006; 40(6): 565-70.

[10] Sullivan JF, Blotcky AJ, Jetton MM, Hahn HKJ, Burch RE. Serum levels of selenium, calcium, copper, magnesium, manganese and zinc in various human diseases. J Nutr 1979; 109: 1432-7.

(C) Khanna et al.; Licensee Bentham Open.

This is an open access article licensed under the terms of the Creative Commons Attribution Non-Commercial License (http://creativecommons.org/licenses/by-nc/3.0/) which permits unrestricted, non-commercial use, distribution and reproduction in any medium, provided the work is properly cited. 